\title{
La multiculturalidad europea: espacio vital de I. Turgénev
}

\author{
Aída Fernández Bueno \\ Departamento de Filología Románica, Filología Eslava y Lingüística General \\ Universidad Complutense de Madrid \\ afbueno@filol.ucm.es
}

\section{RESUMEN}

En la literatura rusa la mirada a occidente, como espacio lingüístico y cultural plural, es una constante. Para los escritores del XIX ruso occidente era un lugar de referencia, y su actitud oscilaba entre la admiración y el rechazo. Sin duda fue Turgénev ${ }^{1}$ el clásico ruso más europeísta y cosmopolita, el que más tiempo vivió fuera de su país de nacimiento. Su exilio físico, en algún momento forzado, dio paso a un alejamiento cultural, idiomático y psicológico de su país. No fue un exilio total; nunca rompió los vínculos con Rusia, pero ya no era posible para él vivir allí. Estaba lejos, instalado en la multiculturalidad y el multilingüismo europeo: bien inglés, alemán, francés o incluso español. Europa se convierte en su patria, especialmente durante sus últimos veinte años. Un amplio espacio que le permite moverse, crear y vivir en libertad.

Palabras clave: multilingüismo, multiculturalidad, cosmopolitismo, Ivan Turgénev

\section{The European Multiculturality: Lifespace of I. Turgénev}

\begin{abstract}
Looking West, as a plural linguistic and cultural space was a constant in the Russian literature. For Russian writers of the nineteenth century the West was a place of reference and without doubts Turgénev, the Russian classic who was the most pro-European and cosmo-

\footnotetext{
${ }^{1}$ La transcripción del ruso al español es un asunto que no está ni mucho menos cerrado, especialmente por lo que se refiere a los nombres propios. Esto se refleja, por ejemplo, en las posibles transcripciones de una misma unidad léxica, lo que para alguien ajeno a temas lingüísticos o filológicos constituye un sinsentido. De ello dan muestra las posibles alternativas que encontramos al citar al autor que nos ocupa: Turgénev, Turguénev, Turgéniev, Turguieniev. Me inclino por la primera de ellas, y en ello siguiendo a Calonge (1969: $25,50)$ quien al estudiar y describir los fonemas rusos define ã como fonema consonántico oclusivo sonoro, y nunca fricativo sordo, por lo que estaría justificada la transcripción de ã por g también ante -e, -i, teniendo el mismo sonido que ante $-\mathrm{a},-\mathrm{o},-\mathrm{u}$.
} 
politan, he who lived the longest time outside his country of birth. His physical exile, sometimes forced, opens a cultural, linguistic and psychological gap from his country. There was no total exile, he never broke ties with Russia, but it was no longer possible for him to live there. He was far away, installed in a multicultural and multilingual Europe: in English, German, French or Spanish. Europe becomes his home country, especially during the last 20 years. A large space with possibilities for him to move, create and live in freedom.

Key words: multilingualism, multiculturality, cosmopolitism, Ivan Turgénev.

La idea de exilio que se ha ido asentando en nuestra sociedad, con la que convivimos actualmente, está cargada de demasiadas connotaciones negativas. El reverso de esa moneda, sin embargo, implica una realidad pluricultural con la que el individuo tiene que coexistir. Tal vez no tanto por lo que atañe a su círculo familiar, que puede ser incluso monocolor, sino por cómo se siente en ese nuevo espacio físico y anímico ajeno, que se habrá de convertir en su entorno de adopción.

En el caso de Turgénev, y para ajustarse a su biografía, habría que invertir los términos y hablar en primer lugar de multiculturalidad, que ciertamente define y determina su realidad desde la infancia, y que se afianzará e intensificará en su vida adulta.

Para muchos será un dato de sobra conocido que Turgénev pertenecía a una familia noble, con sobrados recursos económicos, y que, como hijo favorito que era, tuvo acceso a una educación exquisita para la época. En su casa, en el ambiente doméstico, se respiraba en francés, como en el resto de la nobleza, y en ruso, aprendido en el trato con el personal de servicio. Además Turgénev tuvo instructores privados y dominaba las lenguas de cultura de aquel entonces: el francés, ya mencionado, el inglés, el alemán y el español, que conocía suficientemente bien. Empezó a estudiar en la Universidad de Moscú que por aquellos años, comienzos de los años 30 , era un centro a la vanguardia de la cultura rusa. A la muerte de su padre, su familia se traslada a San Petersburgo en cuya universidad se graduará en 1837. Sus intereses y su curiosidad le llevaron a viajar por Alemania. Allí permaneció entre los años 1838 y 1841, siendo éste un periodo clave en su formación en el que continuó los estudios de Filosofía en la Universidad de Berlín.

A su regreso a Rusia consigue una plaza como funcionario del Estado en San Petersburgo. Esos comienzos de la década de los 40 estarían cargados de importantes acontecimientos que resultarían determinantes en la vida de Turgénev. En primer lugar, en 1843 conoce y traba una fuerte amistad con Besarión Belinski², su mentor y, en cierto modo, responsable de que Turgénev se dedicara finalmente a la actividad lite-

\footnotetext{
2 Besarión Belinski (1811-1848). Crítico literario y publicista ruso. Turgénev y Belinski mantuvieron una buena relación caracterizada por el respeto y cariño mutuos, que fue especialmente intensa en los años previos a la muerte del segundo. A juicio de Turgénev, Belinski poseía la principal cualidad de un crítico, dotado como estaba de una intuición estética infalible y de un sentido y una sensibilidad especiales para la lengua rusa. Era, según Turgénev, un occidentalista convencido, pero siempre desde un profundo amor por Rusia (Turgénev 2000: 53-109).
} 
raria. En segundo lugar, algo que tuvo una trascendencia personal sin igual: ese mismo año conoce a Pauline Viardot ${ }^{3}$. Automáticamente lo ajeno, lo extraño se convierte en próximo, querido y amado. Es bien cierto que a través del otro accedemos a otras realidades, otras lenguas y otras culturas. Y eso fue lo que pasó entre Turgénev y Viardot. Desde ese momento Pauline Viardot y su universo, también cultural, se convierten en una presencia constante en su vida, que se prolongará otros cuarenta años más.

Son muchas las ciudades que dan cuenta de la trayectoria europea de Turgénev, pero destacan tres: París, Baden-Baden y San Petersburgo, por la trascendencia personal y la implicación literaria que tienen ${ }^{4}$.

Cuando Turgénev regresa de su estancia en Berlín, lo hace a San Petersburgo. Allí, en 1843 coincide por primera vez con Pauline Viardot (Fernández Bueno 2010), que se encontraba de gira. Por aquel entonces Pauline ya estaba casada desde hacía tres años con Louis Viardot, pero ambos se enamoraron y enlazaron sus destinos hasta el final de sus días. Esta coincidencia fue hasta tal punto decisiva que a partir de entonces Turgénev seguiría a Pauline y a su familia allá donde ellos fueran, convirtiéndose París y Baden-Baden en epicentros de sus itinerarios vitales. Las dos ciudades fueron, durante el siglo XIX, centros de la cultura europea, receptoras de la intelectualidad y nobleza rusas en estancias más o menos prolongadas. París jugaba con ventaja; su tradición como ciudad de acogida ya se había consolidado.

Baden-Baden, una pequeña y coqueta ciudad en la Selva Negra, al suroeste de Alemania, además de por su balneario y aguas termales, era muy conocida por su famoso casino 5 . Turgénev fue uno de los "visitantes" que más tiempo residió en la ciudad, desde 1863 hasta 1870, y su relación con Baden-Baden fue muy entrañable. En la correspondencia de Turgénev se encuentra una carta a F. Dostoevski, que también visitó Baden-Baden -pero éste, sí, para jugar en su casino-, en la que le manifestaba sus sentimientos y su percepción de la ciudad: le trataban no como a un ruso, sino como a un alemán, y esto constituía para él un motivo de orgullo (apud Wettstein 2003-2006). La familia Viardot se vio obligada a abandonar Francia en 1862 por razones políticas, ya que Louis Viardot no era precisamente un simpatizante de la monarquía ni de Napoleón III. Baden-Baden se convierte en la meta de ese peregrinaje familiar. Pauline Viardot en aquella época, a la edad de 42 años$^{6}$, ya se había ñola.

3 Pauline García Sitches (1821-1910), conocida como Pauline Viardot. Intérprete de ópera franco-espa-

${ }^{4}$ La relación de Turgénev con Europa y sus ciudades queda también reflejada en el nuevo Museo de Turgénev de Moscú, filial del Museo Pushkin. Fue inaugurado el 9 de octubre de 2009 y se encuentra en un inmueble de la calle Ostozhenka que ocupó la familia entre los años 1839 y 1851 . El museo cuenta con importantes fondos, aunque la mayor parte de ellos está repartida entre el Museo de Oriol (Rusia) y el de Bougival (Francia), ciudades en las que nació y murió respectivamente. El museo recoge y muestra una colección de láminas, mapas e imágenes de algunas ciudades que formaron parte del periplo vital de Turgénev: Frankfurt, Berlin, Wiesbaden, Baden-Baden, Basel, Zürich, Stuttgart, París, Londres o Roma.

5 En aquellos años esta ciudad balneario fue muy frecuentada por la nobleza rusa. Un dato muy ilustrativo: hacia 1850 se contabilizaron 5000 visitantes rusos en Baden-Baden, cuando la propia ciudad contaba con un censo de 5000 habitantes. "Baden-Baden und seine russischen Gäste" $<$ http://de.turgenev.de./index. php/2008/07/baden-baden-und-seine-russische-gäste> [Consulta: 8/1/2011].

6 Patrick O’Connor (1949-2010), crítico y autor musical, señala la casualidad de que dos grandes figuras de la interpretación operística, Pauline Viardot y María Callas, se retiraran de los escenarios a la misma edad, 42 años (O’Connor 2007: 16). 
retirado de los escenarios y se dedicaba a su otra vocación, la enseñanza, mientras que Turgénev seguía escribiendo.

En Baden-Baden, Turgénev escribe dos obras que reflejan ese cosmopolitismo europeo que le resultaba tan familiar: la novela Дым (Нито) en 1867, y el relato Вешные воды (Aguas primaverales) en 1870. Podemos hacer una primera distinción derivada del género -la primera es una novela, y la segunda es una nouvelle, una forma entre el cuento y la novela-, pero ambas presentan muchos puntos en común. Se trata básicamente de dos historias de amor en las que se cruza una tercera persona, una mujer, que responde a un patrón de comportamiento muy similar: son personas manipuladoras, seductoras y que vampirizan la mente de los hombres que pretenden. Ellos, por su parte, se muestran sumisos y en cierto grado inmaduros. Los dos protagonistas masculinos se dan cuenta de sus errores $y$, aunque tarde, intentarán recuperar el camino y el tiempo perdidos. En los dos casos podemos encontrar trazas de la propia biografía de Turgénev en los personajes. Concretamente en Aguas primaverales resuena la ópera y se menciona al Maestro García. Las dos obras se desarrollan en ciudades alemanas, Baden-Baden, Frankfurt y Wiesbaden, en una atmósfera multicultural y multilingüe. Además, en el caso de Humo, hay un componente ideológico añadido: Lítvinov y Potúgin ${ }^{7}$, sus protagonistas masculinos más destacados, son acérrimos defensores del occidentalismo, de Europa y lo europeo. Dice Potúgin: "Soy occidentalista, un devoto de Europa [...] un devoto de la cultura [...] de la civilización [...] y la amo de todo corazón, creo en ella" (Turgénev 2004: 49). Sin embargo, respecto a Rusia, su postura es así de contradictoria: "La amo apasionadamente y con la misma pasión la detesto" (Turgénev 2004: 49). Esa europeidad en la que tan cómodamente se movía Turgénev es la misma que defiende en un ensayo un poco anterior, de 1860, Гамлет и Аон Кихот (Hamlet y Don Quijote), cuando muestra sus preferencias por los países que producen tipos como estos dos personajes literarios: “¡Dichosos países aquellos en los que surgen tales hombres, maestros de sus contemporáneos y de la posteridad! El imperecedero laurel que corona a un gran hombre también descansa sobre la frente de su pueblo" (Turgénev 2000: 290).

En la actualidad Baden-Baden conserva, mantiene y activa las huellas de la presencia rusa de manera que, en los años 90 del siglo pasado, se creó la primera de una serie de sociedades (International Baden-Baden Foundation) ocupadas en cuidar el legado de Turgénev en Baden-Baden y de fortalecer el diálogo ruso-alemán.

Este modo de entender la vida instalado en la multiculturalidad, su formación universitaria filosófica y filológica, y sus propias vivencias personales, le servirían para actuar como mittler (intermediario) (Lauer 2005: 116) entre las literaturas europeas, como "живой связующий мост между русской и западноевропейской литературами" (un puente viviente que conecta las literaturas rusa y europea) (Kuleshov 1989: 239), como se refieren a él algunos historiadores literarios. Turgénev fue el escritor más europeísta y occidentalista de todos los grandes clásicos rusos, a la vez que el mejor y más ferviente difusor de la literatura rusa en el extranjero; de Pushkin y de

\footnotetext{
7 Véase nota 1.
} 
Lermontov, pero especialmente de Gógol, Tolstoi y otros no tan conocidos para nosotros como Saltykov-Schedrin. Hay escritores que en su función de críticos, mantienen un punto de vista un tanto diferente -como sería el caso de Nabókov-, que si bien no les desposee de toda su fuerza como escritores, sí atempera y matiza esos planteamientos superlativos. Turgénev era el único escritor ruso conocido, por lo que se decía de él que era el escritor de Rusia (Nabokov 1997: 149). Aún así su trascendencia es incuestionable.

Como dijimos anteriormente, la relación de Turgénev con Pauline Viardot significó acceder a otras realidades culturales y lingüísticas, que entre otras lenguas, también hablaban y escribían en español. Turgénev profundizó en el estudio del español hasta tal punto que, en algún momento de su carrera profesional y ante la mala recepción en Rusia de alguna de sus obras - como fue el caso de Hовь (Suelo vírgen) de 1877-, pensó en la posibilidad de abandonar la escritura y dedicarse a la traducción. De hecho, la traducción de El Quijote era un proyecto en el que le hubiera gustado intervenir. A este respecto dice: "Nosotros, por desgracia, carecemos de una buena traducción del Quijote al ruso [...]. Una buena traducción del Quijote sería muy bien recibida por el público, y un reconocimiento general espera al escritor que nos ofrezca esa obra única en toda su belleza" (Turgénev 2000: 290) . $^{8}$.

La relación de Turgénev con la novela de Cervantes fue prolongada y evolucionó con el transcurso del tiempo, pero a partir del momento en el que conoce a Pauline Viardot y a su familia esa relación se hace más estrecha. En un momento tan crucial para Rusia desde el punto de vista social, en vísperas de la abolición del régimen de servidumbre que ocurriría en 1861, Turgénev escribe el mencionado ensayo Гамлет и Дон Кихот (Hamlet y Don Quijote), que va más allá de ser un mero ejercicio comparatístico. Los personajes adquieren una dimensión social y a través de ellos se bucea en la realidad del XIX ruso, obteniendo algunas claves para su interpretación. Hamlet y Don Quijote personifican dos modelos opuestos. Hamlet representa el escepticismo, mientras que Don Quijote destaca por su confianza y credulidad. Los dos personajes actúan, pero movidos por fuerzas diferentes: Don Quijote lo hará por la voluntad, y Hamlet por el pensamiento, y Turgénev entiende que sólo en la unión, en la asociación de los dos, está la fuerza. Esa asociación de voluntad y de pensamiento es la clave y logra encarnarse, finalmente, en un personaje literario, en una de sus creaciones más memorables y completas, en el protagonista de Omubl и дети (Padres e hijos), el nihilista Evgéni Bazárov.

La razón por la que Turgénev se acerca tanto a lo español se concentra en Pauline Viardot. Quiero dedicar unas palabras a esta mujer única para comprender mejor la calidad artística y el significado de esta comunión entre Turgénev y Viardot.

Pauline García Sitges fue una mujer excepcional, culta, adelantada a su época, inquieta, inconformista, una viajera de alma española. Nacida en una de las familias más artísticas del siglo XIX español, he aquí alguno de sus integrantes más desta-

${ }^{8}$ Este comentario, en apariencia tan objetivo, esconde un subtexto bien diferente. En aquellos años del siglo XIX sí que existía una traducción al ruso, y muy conocida, pero Turgénev no le otorgaba apenas valor literario hasta el punto de preferir ignorarla. Se trata de la traducción que de la novela de Miguel de Cervantes hiciera Vasili Zhukovski en 1804, basada a su vez en una traducción al francés. 
cados: Pauline era la hija menor del tenor y maestro Manuel (del Pópulo Vicente) García y de Josefina Briones (Sitches); hermana de María Malibrán y de Vicente García, también músico, teórico musical, y famoso por ser el inventor del laringoscopio. Todos ellos especialmente dotados para la música en sus múltiples facetas, particularizados, además, por la capacidad de trabajo y la perseverancia, que unido a las especiales dotes interpretativas de Pauline, la distinguen de las demás intérpretes de ópera de la época.

Cuando Pauline tuvo edad para ello, con 19 años, le prepararon un matrimonio de conveniencia con Louis Viardot. Un hombre bastante liberal, también en lo político, políglota como ella, muy cultivado, amigo de los más importantes y reconocidos artistas, y autor de la mejor traducción de El Quijote al francés del siglo $\mathrm{XIX}^{9}$; veinte años mayor que ella y dedicado plenamente a la carrera artística de su esposa.

Pauline García Viardot compartió manteles y sobremesas con lo más granado del círculo cultural del siglo XIX europeo. Fue amiga de muchos, y se relacionó con algunos de los más famosos artistas del ámbito musical: Liszt, Brahms, Schumann, Fauré, Chopin; y también literario, como George Sand, Alfred de Musset o Charles Dickens. Vivió en diferentes capitales europeas en función de la situación política y de sus contratos, y trabajó en los escenarios americanos y europeos más importantes -excepto en los italianos- gracias a la gestión e intermediación de su marido, director del Théâtre Italien de París, y a las relaciones sociales que iban cultivando. Así en el año 1843 le llegó el momento de viajar a Rusia, a San Petersburgo. Allí sería la primera extranjera en cantar un repertorio italiano, contribuyendo enormemente a dar a conocer y traer la música rusa a Occidente. Pero se puso el listón más alto. Cantó canciones rusas en ruso, e incluso llegó a componer algunas. Para poder cantar correctamente los textos de las canciones se aplicó a aprender ruso durante un tiempo con esmero y dedicación, y lo hizo con un maestro de excepción, Iván Turgénev, de manera que logró componer canciones para textos rusos que algunas veces él mismo escribía.

Dos artistas, Pauline Viardot e Iván Turgénev, que compartieron pasiones, y la literatura y la música eran dos de ellas. Pauline aprendió de su padre a amar el Arte, y lo amaba en sus muchas manifestaciones; la literatura era una de ellas. Su marido, hispanista, estudioso de la obra cervantina. Su amante, Iván Turgénev, escritor con reconocido prestigio que gustaba de lo español: su literatura y su lengua. Se enamoró locamente de ella hasta el final de sus días y fue su verdadero amor, aunque uno y otro pasaran por fases de menor fidelidad afectiva. Los dos hombres, el francés y el ruso con un muy fuerte componente intelectual, pero el ruso con casi veinte años menos. Los dos subordinados a Pauline, y Pauline a los dos.

\footnotetext{
${ }^{9}$ Louis Viardot tradujo el Quijote al francés: Miguel de Cervantes Saavedra, L'ingénieux hidalgo Don Quixotte de la Manche (traduit et annoté par Louis Viardot). Paris: J. J. Dubochet, 1836-1837. También se encargó de hacer una semblanza biográfica de Cervantes que aparecería incluída en varias ediciones alemanas del Quijote: Der sinnreiche Junker Don Quixote von la Mancha (aus dem Spanischen übersetzt mit dem Leben von Miguel von Cervantes nach Viardot und einer Einleitung von Heinrich Heine). Stuttgart: Rieger'sche Verlagsbuchhandlung, 1892.
} 


\section{EPÍLOGO}

Hay un momento en el que Turgénev llega también al exilio, no tanto físico como psicológico. Sus últimos 20 años (1861-1881) los vivió fuera de Rusia. Después de Baden-Baden, Turgénev, junto con la familia Viardot, se traslada de nuevo a Francia, a la localidad de Bougival. No existe la imposibilidad de regresar a su tierra, sino una premeditada y meditada voluntad de no retorno. Se produce un distanciamiento emocional tal, que acarrea un extrañamiento respecto del propio país, al que no siente como tal, con el que ya no tiene nada en común; tampoco el pasado. La patria de Turgénev son las personas con las que convive. Pauline Viardot fue su patria, y patria sería todo aquel lugar al que ella fuera.

\section{BIBLIOGRAFÍA}

АГЕКЯН, И. Н., ВОЛЧЕК, Н. М., ВЫСОЦКАЯ, Е. В. и др. (2003): Большой справочник: Весь Русский мир. Вся русская литература. Минск: Современный литератор.

BECK, Ian (2010): “Patrick O'Connor obituary”, en guardian.co.uk. En: http://www.guardian.co.uk/music/2010/feb/23/patrick-o-connor-obituary [Consulta: 12/1/2010].

CALONGE RUÍZ, Julio (1969): Transcripción del ruso al español. Madrid: Gredos.

- (2005): “Trascripción del ruso al español”, en Estudios de lingüística, filología e historia, capítulo XXVI, pp. 405-439. Dispuesto para la imprenta por José Polo. Prólogo de Alberto Bernabé. Madrid: Gredos.

FERNÁNDEZ BUENO, Aída (2010): "Ivan Turguénev y El Quijote: una musical coincidencia”, en Hans Christian Hagedorn, Don Quijote por tierras extranjeras. Cuenca: Ediciones de la Universidad de Castilla-La Mancha.

КУАЕШОВ, В.И. (1989): История русской литературы Х-ХХ века. Москва: Русский язык.

LAUER, Reinhard (2005): Kleine Geschichte der russischen Literatur. München: Verlag C. H. Beck oHG.

NABOKOV, Vladimir (1997): Curso de literatura rusa. Barcelona / Madrid: Ediciones grupo $\mathrm{Z}$.

O'CONNOR, Patrick (2007): Pauline Viardot and friends, Il Salotto vol. 10. ORR 240, Chronology, introduction and notes on songs. London: Opera Rara. Digital Audio CD.

ТУРГЕНЕВ, И. С.: “Встреча моя с Велинским". En: http://dugward.ru/library/belinski/turgenev_vstrecha_s_belinskim.html [Consulta: 14/1/2010].

TURGUÉNIEV, Iván (2004): Humo. Traducción de Víctor Gallego Ballesteros. Barcelona: Alba Editorial.

TURGUÉNIEV, Iván S. (2000): "Hamlet y Don Quijote”, en Páginas autobiográficas, pp. 289-316. Traducción, introducción y notas de Víctor Gallego Ballesteros. Barcelona: Alba Editorial.

- (2000): "Recuerdos de Belinski”, en Páginas autobiográficas, pp. 53-109. Traducción, introducción y notas de Víctor Gallego Ballesteros. Barcelona: Alba Editorial.

- (1992): Suelo virgen. Edición de Manuel de Seabra. Madrid: Cátedra.

TURGUIÉNIEV, Iván S. (1990): Padres e hijos. Introducción y notas de Juan Eduardo Zúñiga. Madrid: Espasa-Calpe.

WAEGEMANS, Emmanuel (1998): Geschichte der russischen Literatur von Peter dem Grossen bis zur Gegenwart (1700-1995). Konstanz: UVK. 
- (1992): Suelo virgen. Edición de Manuel de Seabra. Madrid: Cátedra.

TURGUIÉNIEV, Iván S. (1990): Padres e hijos. Introducción y notas de Juan Eduardo Zúñiga. Madrid: Espasa-Calpe.

WAEGEMANS, Emmanuel (1998): Geschichte der russischen Literatur von Peter dem Grossen bis zur Gegenwart (1700-1995). Konstanz: UVK.

WETTSTEIN, R. (2003-2006): "Iwan Sergejewitsch Turgenejew" y "Russische Promenade", en Russen in Baden-Baden. En: http:/www.russen-in-badenbaden.de/turgenjew.htm [Consulta: 8 en. 2011]. 